\title{
Effects of environmental enrichment on decision-making behavior in pigs
}

\author{
F. Josef van der Staay ${ }^{a, b, *}$, Johanna A. van Zutphen ${ }^{a}$, Mirjam M. de Ridder ${ }^{a}$, \\ Rebecca E. Nordquist ${ }^{\mathrm{a}, \mathrm{b}}$ \\ a Behaviour and Welfare Group (formerly Emotion and Cognition Group), Department of Farm Animal Health, Faculty of Veterinary Medicine, University Utrecht, Utrecht, \\ The Netherlands \\ b Brain Center Rudolf Magnus, Universiteitsweg 100, Utrecht, The Netherlands
}

\section{A R T I C L E I N F O}

\section{Keywords:}

Barren environment

Enriched environment

Decision-making

Animal welfare

Stress

Hair cortisol

Salivary cortisol

\begin{abstract}
A B S T R A C T
The animal's emotional state, potentially modulated by environmental conditions, may affect cognitive processes such as interpretation, judgement and decision making behaviour. The Iowa Gambling Task (IGT) is a common method to examine decision making behavior in humans in terms of risk avoidance and risk taking that reflects the underlying emotional state of the subject. In the present study, we investigated the influence of environmental conditions on decision-making in pigs.

The Pig Gambling task has been developed to assess decision making behavior in pigs,. In this task, the pig can choose between two alternatives. The pigs can make advantageous or disadvantageous choices, where advantageous, low risk choices deliver smaller, but more frequent rewards, whereas disadvantageous, high risk choices yield larger, but less frequent rewards. In the long run, over a series of successive trials, the advantageous choices will yield more reward and less punishment, where punishment consists of delivering reward into the central food trough, but making it inaccessible.

After habituation to testing apparatus and testing methods over the course of approximately 4 weeks, all pigs learned to discriminate between the advantageous and disadvangeous alternatives (acquisition phase) by the age of 9 weeks. After a 14-week retention interval, at the age of 24 weeks, retention performance was tested (retention phase). In both phases, 20 trials per day were given to a total of 120 trials. Saliva and hair samples were collected once at the end of both phases for determining cortisol, and body mass was measured at the end of the retention phase.

The pigs increased the number of advantageous choices during the course of training. In the acquisition phase, barren-housed pigs chose the advantageous options more often compared to environmentally enriched pigs. No differences werer found during the retention phase. All pigs made less advantageous choices at the start of the retention phase than at the end of the acquisition phase. The level of hair cortisol was higher in the barrenhoused than in the enriched-housed pigs. This difference was more pronounced after acquisition than after retention testing. No other differences were found for cortisol in saliva and hair. The environments did not differentially affect body mass at the end of the study. Summarizing, housing in a barren environment appears to be more stressful than housing in an enriched environment, as indicated by higher hair cortisol levels in barrenhoused pigs, but it also improved acquisition of the PGT.
\end{abstract}

\section{Introduction}

Commercially farmed animals face an environment that may exceed their cognitive abilities to adapt successfully (Jensen and Toates, 1993; Korte et al., 2007), which may lead to stress. The animal's emotional state may in turn affect cognitive processes such as interpretation, judgement and decision making (Blanchette and Richards, 2010).

The Iowa Gambling Task (IGT) is a common method to examine decision making in humans, especially risky decision making behavior. The IGT permits measuring the participant's behavior in terms of risk avoidance and risk taking by simulating a real-life decision making situation. The IGT was initially developed to examine the ability of patients with prefrontal cortex damage to make choices under ambiguity (Bechara et al., 1994). The IGT and modifications of this task have subsequently been applied for other research objectives with different clinical neuropsychiatric disorders such as eating disorders (Boeka and

\footnotetext{
* Corresponding author at: Behaviour \& Welfare Group, Department of Farm Animal Health Faculty of Veterinary Medicine, Utrecht University, P.O. Box 80151, 3508 TD Utrecht, The Netherlands.

E-mail address: F.J.vanderStaay@UU.NL (F.J. van der Staay).
} 
Lokken, 2006; Tchanturia et al., 2007), drug abuse (Verdejo-Garcia et al., 2007), pathological gambling (Brand et al., 2005; Linnet et al., 2010), Parkinson's disease (Kobayakawa et al., 2008), depression (Must et al., 2013), ADHD (Garon et al., 2006), and schizophrenia (Matsuzawa et al., 2015). Patients suffering from these psychiatric disorders perform poorly in the IGT. According to Buelow and Suhr (2009), the IGT can be linked to personality and affective state. The notion that the IGT reflects the emotional process of decision-making is supported by studies in which people with anxiety or a negative attitude perform poorer on the IGT than people with a positive attitude (de Vries et al., 2008; Miu et al., 2008; Must et al., 2006; Suhr and Tsanadis, 2007).

Rodent (de Visser et al., 2011b; van den Bos et al., 2014) and pig versions (Murphy et al., 2015) of this task have been developed. The rodent version of the Iowa Gambling Task has been used to investigate the neurobiological mechanisms underlying decision-making (Kempermann et al., 1997; Orsini et al., 2015; Rampon et al., 2000; van Praag et al., 1999). Studies suggest that, just like humans, healthy rats and mice learn to choose the advantageous option (van den Bos et al., 2006).

The PGT, like the IGT, is based on probabilistic learning using rewards and punishments. The probability of responding can be decreased by applying "positive punishment", such as delivery of a painful/noxious consequence, but also by applying "negative punishment", which may consist of withdrawing, withholding, or making inaccessible a positively valued outcome such as food reward (Farhoody, 2012; Mora and Davison, 2009; Sørensen, 2010). Negative punishment might be considered as a less intrusive option than applying positive punishment, where an aversive stimulus is applied (Brando, 2012).

Bechara et al. (2005) distinguished between two phases during the process of learning in a gambling task. During the initial phase, the subject does not yet know the outcome probabilities of choice alternatives, "(the outcomes are known but their probabilities are not known)" (Starcke and Brand, 2012; p. 1230). In this phase, decisions made involve ambiguity. During the course of successive trials, the subjects will learn about the outcome probabilities of the choice alternatives "(the outcome probabilities are specified)" (Starcke and Brand, 2012; p. 1230). Now the subject may choose between safe and risky choices, i.e. the subject may show risk taking or risk avoiding behavior. Safe choices have a high probability of gaining a reward, but the reward is relatively low in value. In contrast, risky choices have a lower probability of gaining a reward, though the reward is substantially larger in value than that of safe choices, which are characterized by a high probability of gaining reward, although the rewards are smaller (Krain et al., 2006).

The pigs can make advantageous or disadvantageous choices, where the advantageous choice is to prefer the smaller, but more frequent rewards above larger, but less frequent rewards (i.e. the disadvantageous choices). In the long run, over a series of successive trials, the advantageous (i.e. safe) choices will yield more reward and less punishment (Brevers et al., 2013) than the disadvantageous (i.e. risky) choices. In the present version of the PGT, (negative) punishment consists of making the reward inaccessible. The optimal strategy thus is to perform advantageous choices yielding smaller reward with less punishment instead of the bigger reward with more punishment (de Visser et al., 2011b).

Rodents that prefer risky choices show the same traits as psychiatric patients suffering from disorders such as mania and drug addiction, in which decision-making is affected (Rivalan et al., 2009; Young et al., 2011).

Since animal welfare can be defined as the quality of life as perceived by the animal (Ohl and van der Staay, 2012), affects and emotions are considered as key elements of an animal's welfare state (Désiré et al., 2002; Mendl and Paul, 2004). Barren environments may provide animals with inadequate mental stimulation, as they restrict the expression of natural behavior. This may lead to stress and unpleasant emotional states (Dawkins, 1990), which, particularly if longer lasting, can lead to a negative affective state that has been associated with poor welfare (Broom, 2011; Duncan and Petherick, 1991; Rushen, 1996). Enriched environments that stimulate the animal's senses and counteract boredom (Ernst et al., 2005) and provide space in which an animal can show natural behaviors, i.e. behaviors which it exhibits under natural conditions (Bracke, 2006), improve animal welfare. Zebunke et al. (2013) studied the effects of cognitive enrichment (a form of environmental enrichment that addresses the cognitive abilities) on behavioral actions and physiological measures of pigs. They found that cognitive enrichment induces a positive affective state in pigs (Zebunke et al., 2013). Physical enrichment such as substrates and objects are challenges for cognitive adaptation. In addition, promoting exploratory and play behavior in pigs is a feasible method to promote positive emotions which enhance overall quality of life (Mills Brown et al., 2015; Zupan et al., 2016).

Various rodent studies have shown that environmental enrichment enhances learning and memory (Kempermann et al., 1997; Rampon et al., 2000; van Praag et al., 1999). Enrichment can modify the structure, growth and physiological efficacy of mammalian neurons and their synaptic connections (Paylor et al., 1992). According to Paylor et al. (1992) altered intracellular signaling and modified synaptic strength may underlie enrichment-induced memory improvement. Sneddon et al. (2000) found that enriched-housed rats learned their task more rapidly than barren-housed rats. These results suggest that cognitive development may be impaired in barren-housed pigs. de Jong et al. (2000) reported that barren-housed pigs had an impaired longterm memory, whereas they showed no differences in learning abilities compared to the enriched-housed pigs.

Recently, the influences of environmental conditions on decisionmaking in rats has been studied. Zeeb et al. (2013) examined the effects of enrichment, social-housing, and isolated rearing on the rat gambling task, a test modelled on the IGT. Compared to rats housed in pairs, isolated animals and environmentally enriched rats learned the optimal strategy slower. The isolated-reared rats, however, were the only ones that, after acquisition of the task, persisted in choosing the disadvantageous option more often than the rats in the other two experimental conditions. It can be concluded from this study that the environment of the animals affects the ability to learn and perform the IGT (Zeeb et al., 2013).

\subsection{Aim of the present study}

Using the Pig Gambling Test (PGT) developed by Murphy et al. (2015) and based on the rodent versions of the IGT, we studied the effects of housing conditions on pigs' decision making behavior. We hypothesized that piglets housed in a barren environment would experience chronic stress and would be slower to learn the optimal strategy and to choose the disadvantageous option more often than littermates housed in the enriched environment. To assess the long-term retention of decision making behavior in the PGT, both groups were tested again after a 14-week rest period. Cortisol in saliva and hair samples, collected immediately after the end of the acquisition and retention phase, was taken as marker of acute and chronic stress, respectively (Antonides et al., 2015; Gieling et al., 2014; Lee et al., 2015). To assess the effects of environmental enrichment on growth, all pigs were weighed at 3 and 26 weeks of age.

\section{Material and methods}

\subsection{Ethical note}

The study was reviewed and approved by the local ethics committee of Utrecht University, The Netherlands, and was conducted in accordance with the recommendations of the EU directive 86/609/EEC. All 
effort was taken to minimize the number of animals used and to avoid any suffering.

\subsection{Subjects and apparatus}

\subsubsection{Animals}

Twenty male piglets (cross-breeds Duroc $\mathrm{x}$ Yorkshire and Duroc $\mathrm{x}$ Danish Landrace) from ten different litters were used. They were born at the farm De Tolakker of Utrecht University in litters sized between 10 and 15 piglets. The parities of sows was not recorded. The tails of all piglets were docked between 3 and 7 days of age. Teeth clipping and castration were not applied.

Starting at one week of age, all piglets had access to a food trough with "Romelko nurse" (supplier: De Heus Voeders B.V., Ede, The Netherlands,), followed by "Romelko prevent 3" in the week before to the first week after weaning.

The experimental animals were selected at 3 weeks of age. Pairs of male piglets closest to their calculated average litter weight were selected and one of the two littermates was assigned randomly to the barren environment, the other to the enriched environment. At the age of 4 weeks, the piglets were weaned, flanks were shaved in the area later to be shaved for cortisol measures, and the animals were moved to the research facility (a stable located next to the stable where they were born). In the research facility, animals were mixed into the final group sizes of 10 animals in their respective environments, (i.e. one barren pen and one enriched pen) (see Fig. 1 for a timeline of this study). All pigs were fed according to weight class as recommended by the feed supplier (de Heus).

\subsubsection{Housing}

Two equally sized, adjacent pens $(5 \mathrm{~m} \times 4 \mathrm{~m})$ were used, one of them providing a barren, the other an enriched environment. Both pens contained a covered piglet nest (approx. $1.3 \mathrm{~m} \times 3.60 \mathrm{~m}$ ). The concrete floor of the enriched pen and the nest area were covered with a thick layer of straw, stimulating rooting behavior (e.g., Averós et al., 2010; Jensen et al., 2008) and exploration (Studnitz et al., 2007). Additional structural enrichment consisted of balls, footballs and wooden sticks on the floor, and plastic chewing sticks and balls attached to chains.

To meet legal requirements, the barren environment contained some enrichment. It was provided with a chain, one ball and two chewing sticks. The floor of the pen and the nest area consisted of bare concrete.

In both pens, water was available ad libitum, and $100 \%$ of the daily feed allowance was provided in the morning on non-training and nontesting days. During training and testing, the pigs received $25 \%$ of their feed allowance in the mornings and the remaining $75 \%$ in the evenings.

\subsubsection{Apparatus}

Testing was conducted in the Pig Gambling test (PGT) apparatus (see Fig. 2), located adjacent to the pigs' pens. A start box $\left(1.2 \mathrm{~m}^{2}\right)$ was connected via an antechamber $\left(1.2 \mathrm{~m}^{2}\right)$ to the test arena $(3.6 \mathrm{~m} \times 2.4 \mathrm{~m})$. The test arena contained two goal boxes, each of which with a food bowl covered by a large, hard plastic ball (diameter: $24 \mathrm{~cm}$ ). The ball could be raised off the bowl but not knocked off. Guillotine doors operated remotely by the experimenter controlled access to the test arena and goal boxes. The swing-doors between the antechamber and test arena always stood fully open, thereby increasing the size of the startbox. The goal boxes were response points. Chocolate M \& M's (Mars Nederland b.v., Veghel, The Netherlands) were used as reward. A food delivery system allowing for delivery of large or small rewards, which could be rendered accessible or inaccessible, was located on the back of the test arena, equidistant between both goal boxes (see Fig. 2B-D). Rewards were placed in two funnels connected to a Y-shaped delivery pipe attached at the back of the apparatus, which fed into a food trough in the test arena (Fig. 2A). The experimenter controlled the release of rewards from either funnel into the food bowl (Fig. 2C). This food trough was covered by a transparent perforated Perspex lid that could only be raised or lowered by the experimenter (Fig. 3D). A number of cues indicated that rewards were present in the food bowl-the sound of the M\&M's dropping down the reward delivery tube into the central food bowl provided auditory cues, while the lid allowed both olfactory and visual perception of the deposited rewards.

\subsection{Test procedures}

\subsubsection{Habituation to apparatus and group training}

After arrival in the research facility, the pigs were left undisturbed for four days. Then, on the following two days, the pigs were habituated to the two experimenters and to chocolate M \& M's. Both groups were separately allowed to leave their home pen and enter the corridor that led to the testing area. One week after arrival, each group was separately allowed to explore the waiting room and the PGT apparatus in three sessions per day on two successive days. Access to the goal boxes was blocked (i.e. the guillotine doors in front of the goal boxes were closed). On the next two days, in two sessions per day, the two groups of ten piglets were allowed to explore the PGT apparatus. The pigs stayed in the start box for approximately $30 \mathrm{~s}$ before they gained access to the testing chamber. Then, the group sizes were first reduced to five and then to two pigs per group over a period of two days (two

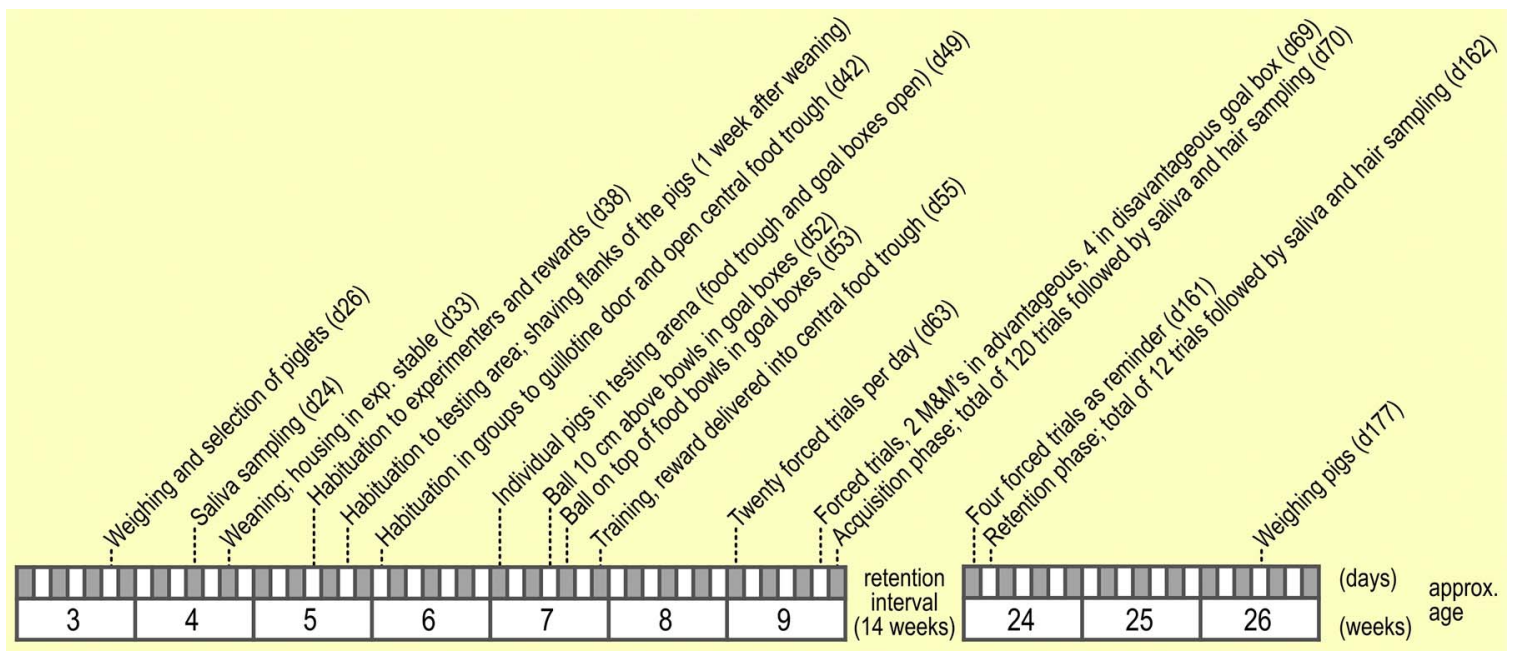

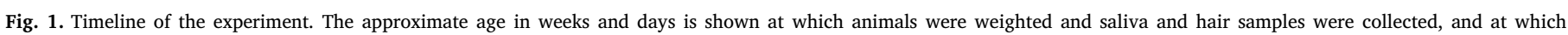
habituation, acquisition and retention testing in the PGT started. 
A

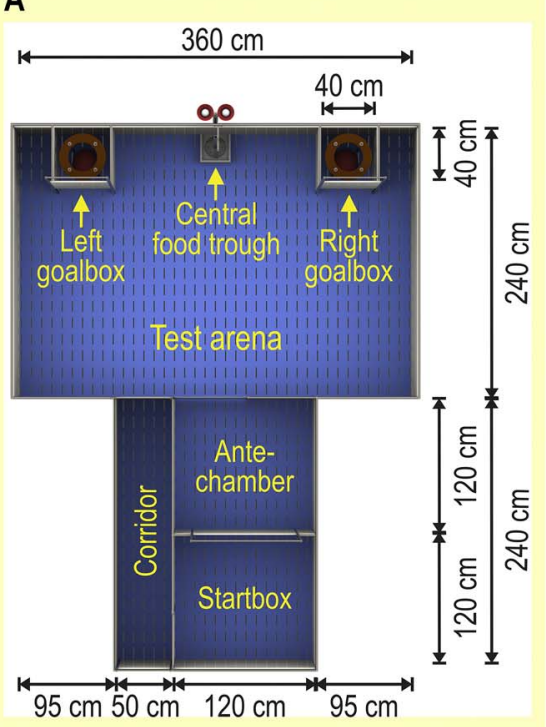

B

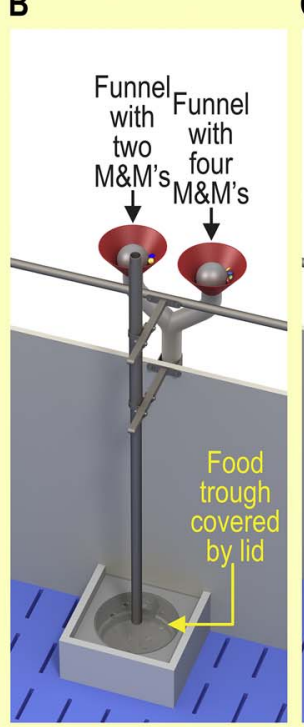

C

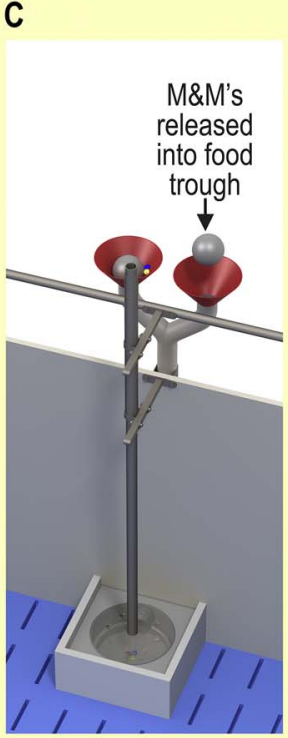

D

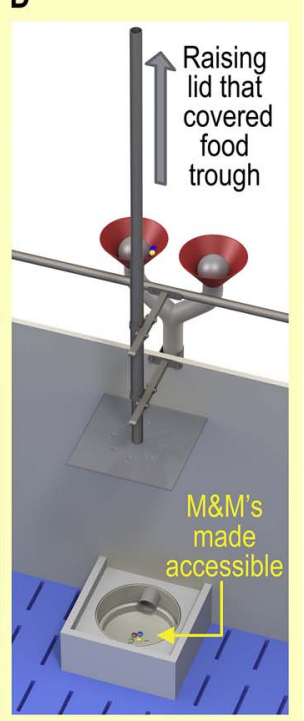

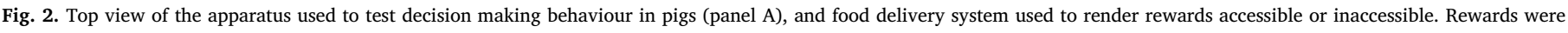

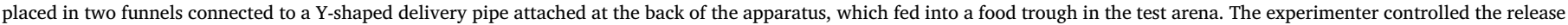

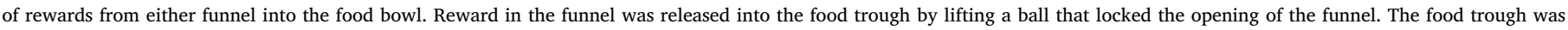
covered by a transparent perforated Perspex lid that could be raised by the experimenter to make reward accessible. (Figures adapted and modified from Murphy et al., 2015).
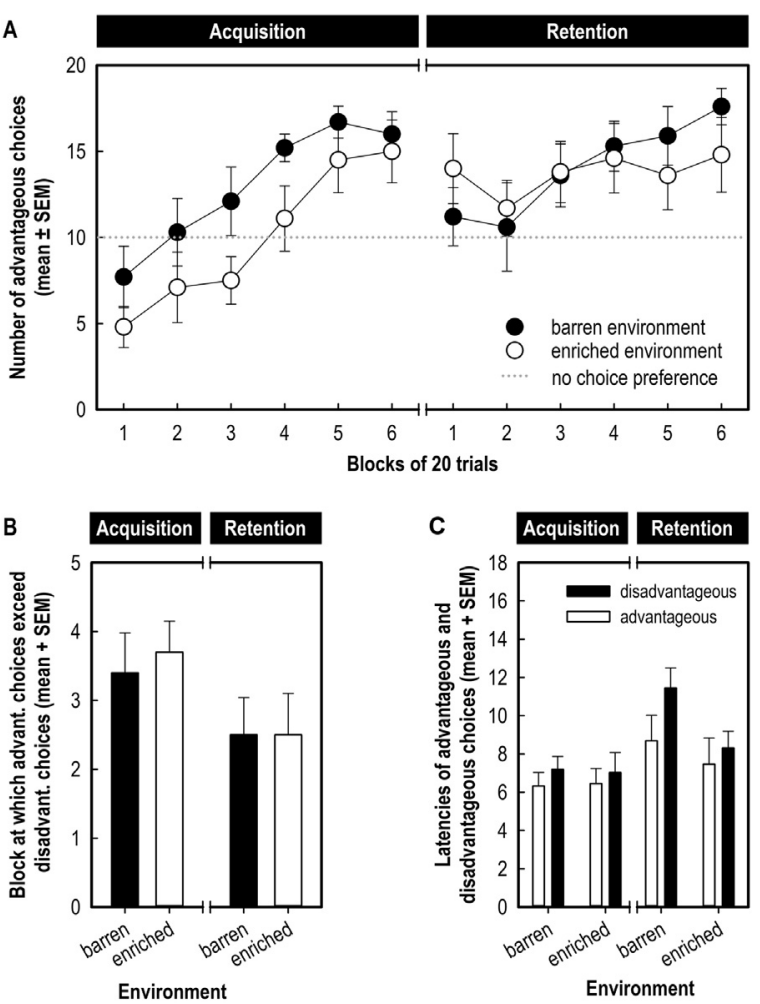

Fig. 3. Number of advantageous choices of pigs kept in a barren or enriched environment from rearing. The number of advantageous choices per block of 20 trials for the acquisition and retention phase is depicted in panel A. Panel B shows the block number during acquisition and retention in which the advantageous choices were higher than the disadvantageous choices. Panel C shows the latencies of advantageous and disadvantageous choices, averaged across all blocks, during the acquisition and retention phase.

sessions per day). On the next two days, in two sessions per day, only one pig was allowed in the testing area. M\&M's were initially scattered in the corners and in the central food trough to encourage exploration. As the sessions continued, the rewards were presented only in the central food trough. When a pig consumed all M\&M's, it was considered to be ready for further training.

\subsubsection{Individual training in the testing apparatus}

A large, red hard plastic ball was hung $10 \mathrm{~cm}$ above the food bowls in the goal boxes which contained a few M\&M's. The pigs were trained to push or lift the ball in order to gain access to these M \& M's in three sessions ( $1 \frac{1}{2}$ day). During the next sessions, the ball in the goal boxes was lowered to entirely cover the food bowl. The pigs were now rewarded with $M \& M^{\prime} s^{\circ}$ in the central food trough for finding the M \& M's in the goal boxes. After three successive sessions in $1 \frac{1 / 2}{2}$ days the pigs were only rewarded in the central food bowl. It took approximately five days of training before all pigs performed the required response to push or lift a ball in order to get the reward in the central food trough.

Some of the pigs always approached the same goal box (side preference). To break this habit, the goal box opposite to their favorite goal box was opened, and the goal box at the preferred side was closed before letting the pig into the testing arena (forced trials). The pigs were given two session each with 10 forced trials for the next five days. Any push that caused movement of the ball was rewarded in the central food trough with two M\&M's ${ }^{\circ}$. Then, the pigs were trained in two sessions per day on 6 successive days, i.e. each pig received 20 trials per day. The left or right goal box was open five times per session in a pseudorandom order. The pigs earned two M\&M's by any push or lift of the ball of their advantageous goal box and a reward of four M \& M's at their disadvantageous goal box. Whether the advantageous side was left or right was randomly determined per pig.

\subsubsection{Acquisition and retention phase}

Next, both goal boxes were open and the pigs could make their choice by any push or lift of the ball in one of the goal boxes. We tested the pigs for six days, one block per day. Each daily block consisted of two 10-trial sessions. A pig was tested 10 times in close succession, with each trial usually lasting between 35 and $70 \mathrm{~s}$. After completion of the tenth trial, the pig left the PGT apparatus. The pigs of the same environment were tested one after another. Then the same procedure was applied in pigs from the other envioronment. This procedure was repeated once per block. After $30 \mathrm{~s}$ in the start box, the guillotine door was opened which allowed the pigs to enter the test arena. Any correct response in a goal box (pushing or lifting the ball) resulted in the delivery of reward into the central food bowl covered by a transparent plastic lid with holes allowing the pig to see and smell the M \& M's. The 
number of $\mathrm{M} \& \mathrm{M}$ 's and the accessibility of reward were predetermined. A response in the advantageous goal box yielded only two M\& M's , but had a high probability (80\%) of becoming accessible. A response in the disadvantageous goal-box yielded four M\& $\mathrm{M}^{\circ} \mathrm{s}^{\circ}$, but with a low probability (30\%) of becoming accessible. In the long run, in each series of 20 trials, the advantageous option yielded 32 accessible M\&M's while the disadvantageous option yielded 24 accessible M\& M's . When a choice was made, the pigs were given $25 \mathrm{~s}$ to consume the reward. If a pig failed to choose within $60 \mathrm{~s}$, both goal boxes were closed and the pig had to stay in the test arena for another $60 \mathrm{~s}$ (time-out period). Then, the pig entered the start box, and the next trials started. This cycle was repeated until the pig had performed the 10 trials of a session. When the acquisition phase ( 6 blocks of two 10trial sessions, i.e. 120 trials in total) was completed, training was suspended.

After a 14-week retention interval testing was resumed. All pigs were first given four forced trials, two with the left and two with the right goal box opened. In these trials the pigs were rewarded with one M \& M's . This session confirmed that all pigs remembered their learned responses. Unlike in the acquisition test, in the retention phase the pigs were large and difficult to seclude in the start box of the apparatus. Therefore, on each of six consecutive days, only one session was given consisting of twenty trials in close succession (6 daily sessions of 20 trials each, i.e. 120 trials in total).

\subsection{Cortisol in saliva and hair}

\subsubsection{Saliva and hair sampling and weighing}

A first saliva sample was taken 2 days before weaning. Unfortunately, the yield of saliva was insufficient to determine cortisol concentrations reliably. The hair at the flank of all piglets was shaved one week after weaning, to determine hair cortisol concentrations and to provide a clean area for hair to grow during the period of housing in enriched or barren environment. Unfortunately, the yield was insufficient to determine cortisol.

One saliva and hair sample was collected immediately after the last (120th) trial of the acquisition phase, and one saliva and hair sample was collected immediately after the last (120th) trial of the retention phase. Saliva samples were taken according to the method described by Merlot et al. (2011). Two swabs (Heinz Herenz, Hamburg, Germany, Cotton Swabs $150 \times 4 \mathrm{~mm}$ WA 2PL) per animal were used to obtain saliva for further analysis. The saliva samples were taken between 14.00 and $18.00 \mathrm{~h}$. Each pig was allowed to chew on the swabs until the swabs were thoroughly moistened. The piglets appraoched the experimenter, and chew the swabs voaluntarily, i.e.hey were not constrained during the sampling.

Then, each pig was picked up and held by one experimenter, and the other shaved the flank of the pig to collect between 0.5 and $1 \mathrm{~g}$ of hair as described by Davenport et al. (2006). Hair samples were stored in aluminum foil at room temperature.

After the last trial of the retention phase, saliva samples were collected again, as described above. However, for hair sampling, pigs were not picked up (the pigs were now habituated very well to the experimenters and allowed shaving without the need to constrain them).

Body weight of all pigs was measured in week 3 and 26.

\subsubsection{Cortisol in saliva}

The swabs were placed in special centrifuge tubes with inner cases (Salivette, Sarstedt, Germany) and were rapidly centrifuged at $3500 \mathrm{G}$ for $10 \mathrm{~min}$ at $10^{\circ} \mathrm{C}$ to obtain the saliva. After discarding the inner case with swabs, the collected saliva was stored in the same tubes at $-20{ }^{\circ} \mathrm{C}$ until cortisol was measured by radioimmunoassay (Merlot et al., 2011), according to the manufacturer's instructions (Coat-a-Count cortisol TKCO, Siemens Healthcare Diagnostics, Los Angeles, USA). All samples from both groups were assayed on the same day in duplicate. The results were given in $\mathrm{nmol} \mathrm{L}^{-1}$.

\subsubsection{Cortisol in hair}

For analysis of hair cortisol, between 50 and $250 \mathrm{mg}$ hair was washed twice by gently mixing (roller-bank speed 20) for $3 \mathrm{~min}$, with $5 \mathrm{ml}$ isopropanol in a $50 \mathrm{ml}$ tube for minimizing contamination of cortisol measurements with cortisol from feces and urine (Davenport et al., 2006). The hair was dried in a stove (Memmert, Depéx, De Bilt) at $37^{\circ} \mathrm{C}$ for four days. About $50 \mathrm{mg}$ was weighed using a precision scale (analytic balance AE240, Mettler Toledo B.V., The Netherlands) and placed in a snapcap Eppendorf centrifuge tube $(2 \mathrm{ml})$. The hair samples were ground in a TissueLyser II (Qiagen, The Netherlands) with 3 beads (3.2 $\mathrm{mm}$ no 11079132, Qiagen, The Netherlands) per sample for $15 \mathrm{~min}$ at $30 \mathrm{~Hz}$ and subsequently centrifuged $\left(17000 \mathrm{G}, 5 \mathrm{~min}\right.$ at $4{ }^{\circ} \mathrm{C}$ ) (Sigma 3K10 Laborzentrifugen, Salm en Kipp B.V., The Netherlands). Grinding and centrifuging were repeated, if a sample was not pulverized.

Twenty-five to $45 \mathrm{mg}$ of the fine powder was placed in a snapcap Eppendorf centrifuge tube, according to the method described by Scholman (2012) and Zeinstra et al. (2015). One $\mathrm{ml}$ of methanol was added to every tube and tubes were incubated at room temperature, protected from light, for $24 \mathrm{~h}$ while slowly rotating on a tube-rotator (Snijders test-tube-rotator 34528, Omnilabo International B.V., The Netherlands). The tubes were then centrifuged at $17,000 \mathrm{~g}$, for $5 \mathrm{~min}$ at $4{ }^{\circ} \mathrm{C}$. Subsequently, $0.6 \mathrm{ml}$ of the clear extract was taken and placed in a new tube and stored at $4{ }^{\circ} \mathrm{C}$. For further analysis, the extracts were dried in a Speedvac (AES 1000, Savant Instruments Inc. Farmingdale $\mathrm{NY}$ ) for $2.5-3 \mathrm{~h}$, medium temperature, and then stored at $-20^{\circ} \mathrm{C}$. The dried extracts were dissolved in $100 \mu$ l phosphate buffer (assay diluent), provided in the High Sensitivity Salivary Cortisol ELISA kit (Salimetrics Europe Ltd., Newmarket, United Kingdom), for $24 \mathrm{~h}$ at a shaker set at $300 / \mathrm{min}$. The samples were again stored at $-20^{\circ} \mathrm{C}$. The Elisa kit was further used according to the manufacturer's instructions. All analyses were performed in duplicate. The obtained optical densities were corrected for dilution and the actual amount of hair powder that had been used. Cortisol concentrations were expressed in $\mathrm{ng} \mathrm{mg}^{-1}$ hair.

\subsection{Statistical analysis}

All analyses were performed using the statistical software SAS (version 9.4, SAS Institute, Cary, NC, USA). Normal distribution of the residuals of all dependent variables was assessed using the ShapiroWilk test (SAS PROC UNIVARIATE).

\subsubsection{Number of advantageous choices}

The effects of the rearing environments on the number of advantageous choices were analyzed using a mixed model analysis of variance (ANOVA; SAS PROC MIXED) with the fixed effects. Environment (barren, enriched) and six successive Trialblocks (a block consisting of the number of advantageous choices in each series of 20 daily trials), and their interactions separately for the acquisition and the retention phase. In addition, to assess the effects of the 14-week retention interval, we compared the performance during the last (6th) block of the acquisition phase with the first of the six blocks of the retention phase. In all mixed model analyses, a random effect for litter was added, and the correlation of repeated measures within piglets was addressed using an autoregressive heterogeneous (1) [AHR(1)] structure for the residuals.

\subsubsection{Session from which the number of advantageous choices exceeded the number of disadvantageous choices}

The effect of the environment on the number of acquisition sessions needed until the number of advantageous choices exceeded the number of disadvantageous choices was analyzed using a mixed model ANOVA. 
A
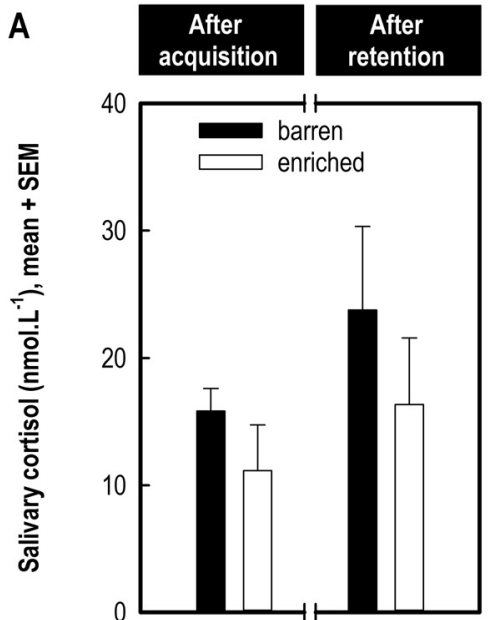

B
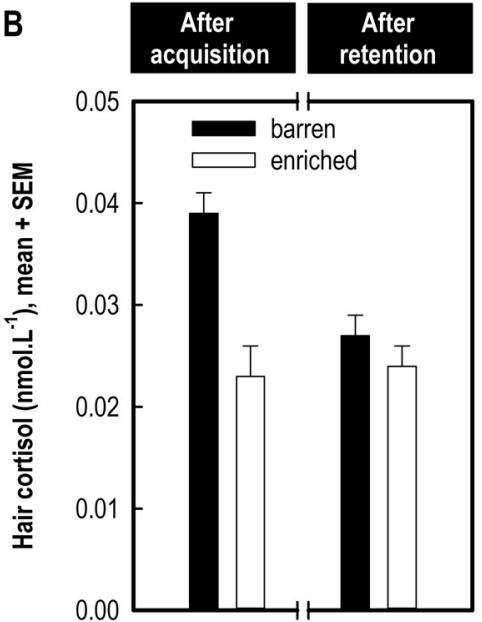

C

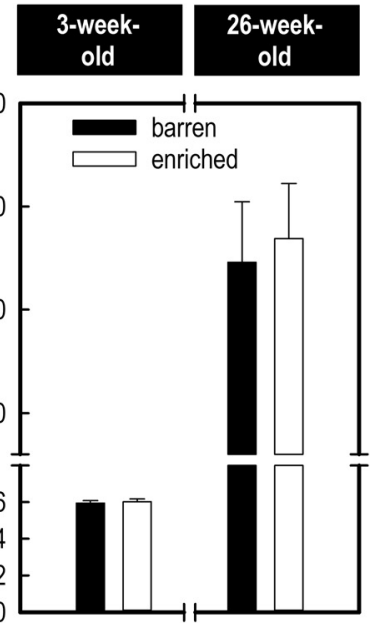

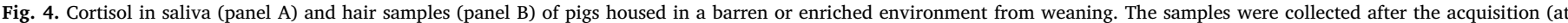

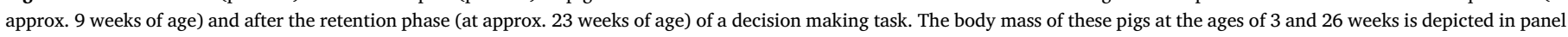
C. The means and standard errors of the means of two groups of 10 pigs are shown.

\subsubsection{Difference score between latencies of advantageous and} disadvantageous choices

Mean difference scores between latencies of advantageous and disadvantageous choices were calculated across blocks per phase (acquisition, retention) and analyzed in a mixed model ANOVA with the fixed factors Environment and Phase (acquisition, retention). Note that some pigs in some sessions did not make any advantageous or disadvantageous choice. In that case, a missing value was entered in the data sheet.

\subsubsection{Salivary and hair cortisol}

The effects of the rearing environment on salivary and hair cortisol were analyzed using a mixed model ANOVA with the fixed effects Environment (barren, enriched) and Sampling time point (samples drawn after the acquisition and after the retention phase of the PGT).

\subsubsection{Body mass}

The effects of the rearing environment on body mass were analyzed using a mixed model ANOVA with the fixed effects Environment (barren, enriched) and Age (3 vs. 26 weeks of age).

\section{Results}

\subsection{Advantageous choices}

The number of advantageous choices increased across the 6 successive trialblocks of the acquisition phase $\left(\mathrm{F}_{5,99}=12.29\right.$, $\mathrm{P}<0.0001$; Fig. 3A), similarly in both groups (Trialblocks by Environment interaction: $F_{5,99}=0.41, P=0.842$ ). The barren-housed pigs made more advantageous choices than the enriched-housed littermates $\left(\mathrm{F}_{1,99}=4.27, \mathrm{P}=0.041\right)$.

In the retention phase, the number of advantageous choices increased marginally across blocks (Trialblocks, $\mathrm{F}_{5,99}=2.11$, $\mathrm{P}=0.070$; Trialblocks by Environment interaction: $\mathrm{F}_{5,99}=0.78$, $\mathrm{P}=0.566$ ). The Environment did not affect the number of advantageous choices in the retention phase.

The number of advantageous choices decreased between the end of the acquisition (6th block of the acquisition phase) and the start of the retention phase (1st block of the retention phase) $\left(F_{1,27}=7.01\right.$, $\mathrm{P}=0.013$ ), but this drop was not affected by Environment (Environment, $\quad \mathrm{F}_{1,27}=0.19, \quad \mathrm{P}=0.684 ;$ Retention interval by Environment interaction, $\mathrm{F}_{1,27}=3.01, \mathrm{P}=0.094$ ).
3.2. The trialblock at which the advantageous choices exceed the disadvantageous choices

The block of trials at which the number of advantageous choices exceeded those of the disadvantageous choices was unaffected by the environment (acquisition phase, $\mathrm{F}_{1.27}=0.17, \mathrm{P}=0.688$; retention phase, $F_{1,27}=0.00, P=1.000$; see Fig. $3 \mathrm{~B}$ ).

\subsection{Latencies of advantageous and disadvantageous choices}

Visual inspection of Fig. 3C suggests that the barren-housed pigs had a longer mean latency to respond to the disadvantageous option than to the advantageous one. This impression, however, was not confirmed statistically (Environment: $\quad \mathrm{F}_{1,27}=0.54, \quad \mathrm{P}=0.4703$; Phase: $\mathrm{F}_{1,27}=0.99, \quad \mathrm{P}=0.3286$; Environment by Phase interaction: $\left.\mathrm{F}_{1,27}=0.55, \mathrm{P}=0.4643\right)$.

\subsection{Salivary and hair cortisol}

Shapiro Wilk test indicated that all cortisol values were distributed normally.

\subsubsection{Cortisol in saliva}

There was neither an effect of environment nor of sampling time points following the acquisition and retention phases (Environment: $\mathrm{F}_{1,27}=1.68, \quad \mathrm{P}=0.2058$; Sampling time point: $\mathrm{F}_{1,27}=2.29$, $\mathrm{P}=0.1418$; Environment by Sampling time point interaction: $\left.\mathrm{F}_{1,27}=0.10, \mathrm{P}=0.7567\right)$ on salivary cortisol.

\subsubsection{Cortisol in hair}

The rearing environment affected hair cortisol differently (Environment: $\mathrm{F}_{1,24}=15.54, \quad \mathrm{P}=0.0006$; Sampling time point: $\mathrm{F}_{1,24}=4.09, \mathrm{P}=0.0545$; Environment by Sampling time point interaction: $F_{1,24}=6.71, P=0.0160$ ). Hair cortisol was higher in barrenhoused than enriched-housed pigs (see Fig. 4B) and this difference was more pronounced after acquisition than after retention testing.

\subsection{Body mass}

Body mass and growth were not affected by the rearing environment (Environment: $\mathrm{F}_{1,27}=0.09, \mathrm{p}=0.7703$, Age: $\mathrm{F}_{1,27}=653.13$, $\mathrm{P}<0.0001$; Environment by Age interaction: $\mathrm{F}_{1,27}=0.08$, $\mathrm{P}=0.7773$; see Fig. 4C). 


\section{Discussion}

\subsection{Acquisition and retention}

The barren-housed pigs had higher levels of hair cortisol concentrations than the enriched-housed pigs. According to Conrad (2010), chronic stress in rats has an influence on hippocampal functioning, including spatial learning and working memory. Oitzl and de Kloet (1992) showed that very low or high concentrations of circulating corticosterone impair spatial learning in rats. Environmental enrichment has been shown to improve spatial abilities in rats (Paylor et al., 1992), and improved spatial working memory in pigs (GrimbergHenrici et al., 2016). These findings do not match with our current results.

In the acquisition phase, the barren-housed pigs chose the advantageous side more often compared to the enriched-housed pigs. Visual inspection of the data suggested that the barren-housed pigs learned faster, i.e. had a steeper learing curve, an impression that was not confirmed statistically. Also, the number of blocks at which the advantageous choices exceeded disadvantageous choices in the acquisition and retention phase were not affected by the environment. The barren-housed pigs in the acquisition phase may be better at weighing the probabilities of each choice in order to maximize their gain, suggesting a better working memory. Note that in the initial phase of the PGT, the subject does not yet know the outcome probabilities of choice alternatives (Starcke and Brand, 2012) but must "detect" this probability by remembering the outcomes of a series of successive trials. In this phase, decisions made initially involve ambiguity. The barren housed pigs may have detected the underlying probabilities faster than the enriched housed ones. This corroborates the findings of Zeeb et al. (2013) that rats housed in enriched environments were slower learners. However, it does not corroborate research by Sneddon et al. (2000), where enriched-housed pigs learned faster than barrenhoused pigs, suggesting that the cognitive development of barrenhoused pigs may have been impaired. In the acquisition phase, the barren- and enriched-housed pigs showed an increasing preference for the advantageous side, althought the learning curve of the barrenhoused pigs were higher than that of the enriched housed pigs. Both groups eventually reached a similar performance level.

According to de Jong et al. (2000), who used a retention interval of nine weeks, pigs housed in a barren environment have an impaired long term memory compared to enriched-housed pigs. We used a retention interval of 14 weeks and observed no difference in the long term memory between the two groups

On the other hand, Douglas et al. (2012) found that pigs housed in an enriched environment showed an optimistic cognitive bias in a judgment bias task, which was interpreted as indicative of a positive affective state.

\subsection{Latencies}

The latencies of disadvantageous choices seemed to be longer than the latencies of advantageous choices. However, this impression was not confirmed statistically. Longer response times in memory tests have generally been associated with incorrect choices compared to correct choices (Laughlin and Mendl, 2004).

\subsection{Affective state}

Our expectation was that the behavior of the barren-housed pigs would be comparable with that of rats preferring risky choices is consistent with the experimental observations. The negative affective state of pigs that may be induced by a barren environment (Douglas et al., 2012) did not lead to choosing the disadvantageous option more frequently.

Non-systematic observations during the course of the experiment may shed some light on the differences in behavior between the groups reared in the barren and enriched environment. Compared to the barren-housed pigs, the enriched-housed pigs showed more anxious behavior by moving back more often and quicker when the experimenters approached them. They seemed, however, to react less anxiously to new stimuli, possibly because of the enrichment in their pen. The barren-housed group was more cooperative than pigs from the enriched environment. In line with de Visser et al. (2011a), where high anxiety in rats led to reduced performance (they less frequently chose the advantageous option), the enriched-housed pigs underperformed in the acquisition phase compared to the barren-housed pigs by choosing the advantageous side less often.

The PGT as derivative of the Iowa Gambling Task involves decision making processes (Brand et al., 2007). During the initial phase of the PGT, the subject does not yet know the outcome probabilities of choice alternatives. Consequently, decisions made involve ambiguity. Later trials reflect decision making under risk where the subject learns about the potential outcomes. All pigs of the present study from both environments showed a stronger preference for the advantageous option over the course of acquistion, but the barren-housed pigs made more advantageous choices. This suggests that barren-housed pigs show a higher aversion to risk compared to the enriched-housed pigs instead.

\subsection{Training as enrichment}

It is probably incorrect to say that the barren-housed pigs did not experience any enrichment. They experienced, just as the enrichedhoused pigs, attention daily, in the period of habituation to the testing equipment and procedures, and during training and testing in the PGT apparatus. Training affords learning opportunities and learning is considered to be enriching. However, according to a study of Melfi (2013) there are more conditions that have to be met before being considered as enrichment. The training should, for example, provide a dynamic change of the animals' day and should increase animal-human interactions, conditions met by the present study.

Similar to other forms of environmental enrichment, training may alleviate stress, increase species specific behavior, biological function (e.g. brain development, physical fitness and health), flexibility, behavioral diversity, and exploration (Melfi, 2013). Environmental enrichment also reduces abnormal behavior such as stereotypies (Hunter et al., 2002; Moreira et al., 2007; van Hoek and King, 1997). Training thus may have added enrichment and affected the behavior of the pigs reared in barren or enriched environment (see also Grimberg-Henrici et al., 2016)

\subsection{Contingencies in the PGT}

A number of potential contingencies underlying the advantageous and disadvantageous choices in the PGT can be distinguished (see Fig. 5).

Pigs may choose (I) the preferred side (side preference, side bias), (II) the side yielding the larger reward (more M \& M's ${ }^{\circ}$ ), (III) the side that yields reward with the highest probability, (IV) the side that yields the fewest punishments, i.e. impedes consumption of the M\& M's in the central food bowl, or finally, (V) pigs may choose the side that, within a series of, for example, 10 trials, yields the largest number of M \& M's (van der Staay et al., 2016). It remains to be proven that pigs are able to assess the long-term probabilities of earning the maximum number of reward/minimum number of punishment. Instead, they may simply choose the contingency that provides the largest probability to gain reward in a trial, whereas the number of chocolate M \& M's may be less relevant.

Moreover, Anselme (2015) raised doubts whether this type of tasks models decision-making under risk, because failing to gain the maximum of $32 \mathrm{M} \& \mathrm{M}$ 's ${ }^{\circ}$ per series of 20 trails has no serious consequences. M \& M's were released into the central food bowl upon lifting the ball 


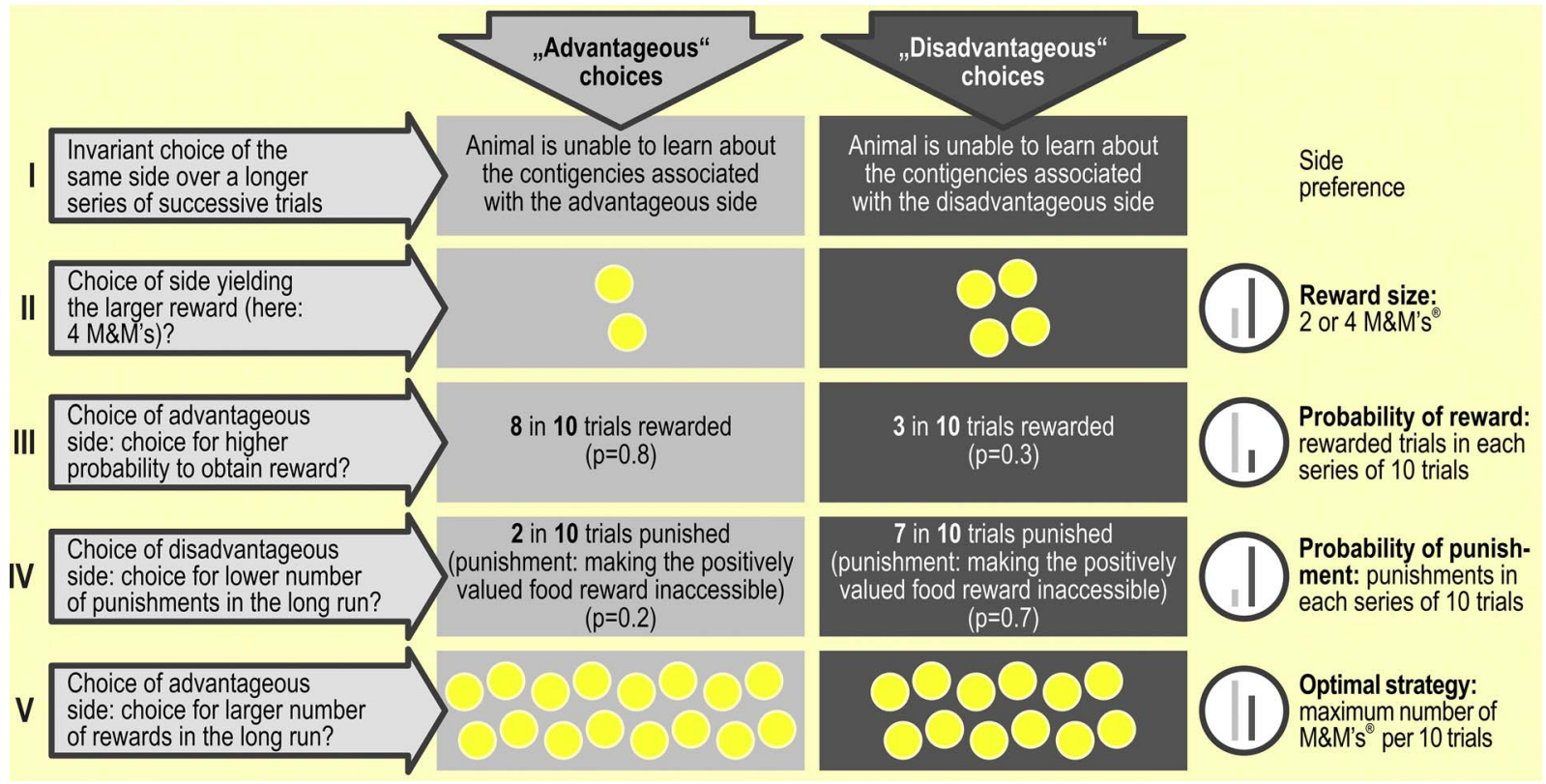

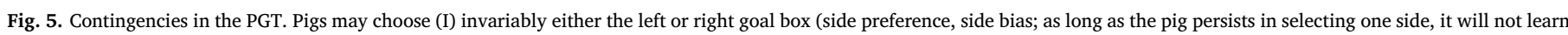

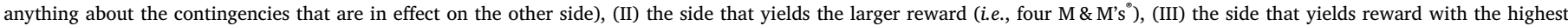

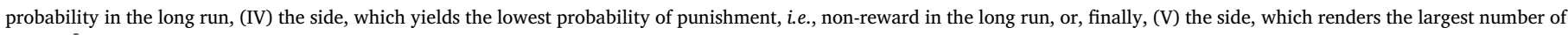

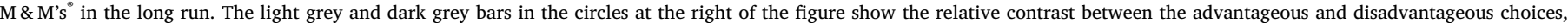

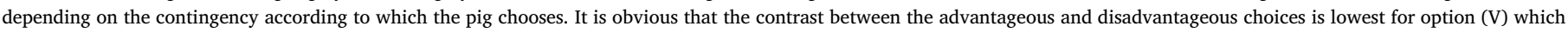
represents the contingencies that the pig is believed to learn in the PGT (modified from van der Staay et al., 2016).

in one of the goal boxes. The sound of the falling M \& M's may act as secondary reinforcer that helped to maintain responding. M \& M's ${ }^{\circ}$ made accessible for consumption acted as primary reinforcer, whereas leaving the M\&M's inaccessible after hearing the sound of M\&M's falling into the food trough and seeing and smelling the reward in the trough may have been experienced as (mild) punishment.

\subsection{Putative effects of flavonoids in $M \& M$ 's as cognition enhancers}

Whereas it is feasible that the M \& M's ${ }^{\circledR}$ promoted the pigs' learning because of their rewarding effects, they possibly also have cognition enhancing effects through the flavonoid components, in particular flavanols in chocolate (for reviews see Field et al., 2011; Sokolov et al., 2013). One M \& M's weighs $0.9 \mathrm{~g}$, and each M\& M's contains $70 \%$ cacao. Fifty M \& M's have a total weight of $31.9 \mathrm{~g}$ of cacao.

A single administration of $100 \mathrm{mg}$ cacao per $100 \mathrm{~g}$ body weight significantly reduced fear conditioning in rats. Long-term administration (two weeks) enhanced brain concentration of the emotion-related neurotransmitter serotonin and its turnover (Yamada et al., 2009). Short-term cocoa intake has an anxiolytic effect, whereas long-term intake affects brain monoamine metabolism (Yamada et al., 2009). In animal models of normal aging, dementia, and stroke, protective effects of long-term flavanol consumption on behavior and neurocognition, including disease- and age-related cognitive decline, were shown. Human research corroborates these findings (reviewed in Sokolov et al., 2013). Given the actions of flavanols in cacao, cacao may be considered a cognition enhancer (van der Staay et al., 2011). Whereas cognition-enhancing effects have been shown with much higher doses of chocolate than in the present study, we cannot completely reject the possibility that very small amounts of cacao already enhance cognition, for example by potentiating enrichment effects of testing. Such (combined) effects may have masked potential effects that housing had on performance in the PGT.

\subsection{Pen size}

The pigs in the present study had more space than conventionally housed pigs. According to Varkensbesluit (Pigs Decree) 2013, article 4 (Pigs decree - Dutch Government, 2015) it is required to provide pigs under $15 \mathrm{~kg}$ with $0.20 \mathrm{~m}^{2}$ space per pig. From 15 up to $30 \mathrm{~kg}$ and $30 \mathrm{up}$ to $50 \mathrm{~kg}$ the pigs must have $0.40 \mathrm{~m}^{2}$ and $0.60 \mathrm{~m}^{2}$ space per pig, respectively. At a weight of $50-85 \mathrm{~kg}$ and $85-110 \mathrm{~kg}$, pigs must have $0.80 \mathrm{~m}^{2}$ and $1 \mathrm{~m}^{2}$ space per pig, respectively. Each pig in the present study had access to $2 \mathrm{~m}^{2}$ space throughout the entire experiment (at the end of the study, when the pigs had reached 26 weeks of age, the body weight of the barren-housed pigs was (mean \pm standard error of the mean) $104.60 \pm 5.86 \mathrm{~kg}$, that of the enriched housed pigs was $106.90 \pm 5.33 \mathrm{~kg}$; see also Fig. 4C). The generous space allowance may influence the results because more living space may also provide some enrichment. It is suggested that a higher space allowance enhances the exploration towards the non-social environment within the pen, and reduces the occurrence of aggressive episodes (Averós et al., 2010). The time spent exploring increases with space allowance, but only when bedding is provided (Averós et al., 2010; Turner et al., 2003), which was not available in the barren environment.

\subsection{Salivary and hair cortisol}

According to Beattie et al. (1995) a barren environment has negative effects on pig welfare. Cortisol levels are often used to assess chronic stress and to subsequently judge animal welfare. In our experiments the cortisol level in hair was higher in the barren-housed pigs compared to enriched-housed pigs in the first 5 weeks following enriched- or barren housing, but not in the samples collected after an additional 14 weeks of enriched or barren housing. The increased hair cortisol concentrations, which reflect a long-term measure of stress (i.e. Short et al., 2016) in the present study suggests that barren-housed pigs experienced more stress during the first few weeks of housing in the experimental environment. Grimberg-Henrici et al. (2016) found that pigs in a barren environment had increased basal cortisol concentrations in saliva, which would support the present finding. de Jong et al. (2000) also found differences in basal salivary cortisol levels between enriched and barren- housed pigs, but the study by De Jong and colleagues reported lower salivary cortisol levels in barren- than 
enriched-housed pigs which were both circadian- and age-dependent. In fecal cortisol, which is presumed to reflect responses over several hours, no effect was seen of environmental enrichment on cortisol levels in pigs (Cornale et al., 2015). This discrepancy underlines the difficulty in the interpretations of basal levels of acute measures of cortisol, i.e. in saliva and blood and to a certain extent feces, as a reflection of long-term effects. Hair cortisol, which does not reflect temporally short responses in terms of minutes or hours but a gradual buildup over weeks, may provide a better reflection of long-term effects of housing on the HPA-axis.

In the present study, no housing effects were found for cortisol levels in saliva following a behavioral challenge. The results reported in literaure regarding acute responses of cortisol in either blood or saliva of enriched-housed animals are not always consistant. In goats housed in enriched or barren environments, no effect of environment was found on salivary cortisol following a behavioral challenge (Oesterwind et al., 2016), in agreement with the lack of effect of behavioral challenge on salivary cortisol response in the present study. However, in blood, environmentally enriched pigs showed a trend to increased response to a behavioral challenge compared to barren-housed pigs (Beattie et al., 2000). Salivary cortisol concentrations were measured at a single time point after testing in the present study as a measure of acute cortisol response to a challenge. The use of a single time point is a limitation of the current study; it is possible that if more time points had been included pre- and/or post-testing, an effect of environment on salivary cortisol may have been seen.

\section{Conclusion}

Housing conditions affected PGT performance. In the acquisition phase, barren-housed pig performed better, i.e. made more advantageous choices than the enriched-housed pigs, whereas no differences between the two groups of pigs were seen during the retention phase. The barren-housed pigs had higher hair cortisol levels, suggesting that the barren environment was more stressful than the enriched environment.

\section{Declaration of interest}

The authors declare no conflict of interest.

\section{Acknowledgements}

We would like to thank the animal caretakers of the university farm De Tolakker for assisting with the collection of saliva and hair samples for determining cortisol, and for taking care of the pigs during the retention period. We would also like to thank Elly Zeinstra and Christine Oei for their guidance and advices in the laboratory and their help with the measurements of cortisol in saliva and hair samples. The present study has been funded by the Department of Farm Animal Health, Faculty of Veterinary Science, Utrecht University.

\section{References}

Anselme, P., 2015. Does reward unpredictability reflect risk? Behav. Brain Res. 280, 119-127. http://dx.doi.org/10.1016/j.bbr.2014.12.003.

Antonides, A., Schoonderwoerd, A.C., Nordquist, R.E., van der Staay, F.J., 2015. Very low birth weight piglets show improved cognitive performance in the spatial cognitive holeboard task. Front. Behav. Neurosci. 9, 10. http://dx.doi.org/10.3389/fnbeh. 2015.00043.

Averós, X., Brossard, L., Dourmad, J.-Y., de Greef, K.H., Edge, H.L., Edwards, S.A., Meunier-Salaün, M.-C., 2010. A meta-analysis of the combined effect of housing and environmental enrichment characteristics on the behaviour and performance of pigs. Appl. Anim. Behav. Sci. 127, 73-85. http://dx.doi.org/10.1016/j.applanim.2010.09. 010.

Beattie, V.E., Walker, N., Sneddon, I.A., 1995. Effects of environmental enrichment on behaviour and productivity of growing pigs. Anim. Welf. 4, 207-220.

Beattie, V.E., O'Connell, N.E., Kilpatrick, D.J., Moss, B.W., 2000. Influence of environmental enrichment on welfare-related behavioural and physiological parameters in growing pigs. Anim. Sci. 70, 443-450.
Bechara, A., Damasio, A.R., Damasio, H., Anderson, S.W., 1994. Insensitivity to future consequences following damage to human prefrontal cortex. Cognition 50, 7-15. http://dx.doi.org/10.1016/0010-0277(94)90018-3.

Bechara, A., Damasio, H., Tranel, D., Damasio, A.R., 2005. The Iowa Gambling Task and the somatic marker hypothesis: some questions and answers. Trends Cognit. Sci. 9 , 159-162. http://dx.doi.org/10.1016/j.tics.2005.02.002.

Blanchette, I., Richards, A., 2010. The influence of affect on higher level cognition: a review of research on interpretation, judgement, decision making and reasoning. Cognit. Emot. 24, 561-595. http://dx.doi.org/10.1080/02699930903132496.

Boeka, A.G., Lokken, K.L., 2006. The Iowa gambling task as a measure of decision making in women with bulimia nervosa. J. Int. Neuropsychol. Soc. 12, 741-745. http://dx. doi.org/10.1017/S1355617706060887.

Bracke, M.B.M., 2006. Providing cross-species comparisons of animal welfare with a scientific basis. NJAS - Wagening J. Life Sci. 54, 61-75. http://dx.doi.org/10.1016/ S1573-5214(06)80004-7.

Brand, M., Kalbe, E., Labudda, K., Fujiwara, E., Kessler, J., Markowitsch, H.J., 2005 Decision-making impairments in patients with pathological gambling. Psychiatry Res. 133, 91-99. http://dx.doi.org/10.1016/j.psychres.2004.10.003.

Brand, M., Recknor, E.C., Grabenhorst, F., Bechara, A., 2007. Decisions under ambiguity and decisions under risk: correlations with executive functions and comparisons of two different gambling tasks with implicit and explicit rules. J. Clin. Exp. Neuropsychol. 29, 86-99. http://dx.doi.org/10.1080/13803390500507196.

Brando, S.I.C.A., 2012. Animal learning and training - implications for animal welfare. Vet. Clin. North Am. Small Anim. Pract. 15, 387-398. http://dx.doi.org/10.1016/j. cvex.2012.06.008.

Brevers, D., Bechara, A., Cleeremans, A., Noël, X., 2013. Iowa GamblingTask (IGT): twenty years after - gambling disorder and IGT. Front. Psychol. 4, 14. http://dx.doi. org/10.3389/fpsyg. 2013.00665.

Broom, D.M., 2011. A history of animal welfare science. Acta Biotheor. 59, 121-137. http://dx.doi.org/10.1007/s10441-011-9123-3.

Buelow, M.T., Suhr, J.A., 2009. Construct validity of the Iowa Gambling Task. Neuropsychol. Rev. 19, 102-114. http://dx.doi.org/10.1007/s11065-009-9083-4.

Conrad, C.D., 2010. A critical review of chronic stress effects on spatial learning and memory. Prog. Neuropsychopharmacol. Biol. Psychiatry 34, 742-755. http://dx.doi. org/10.1016/j.pnpbp.2009.11.003.

Cornale, P., Macchi, E., Miretti, S., Renna, M., Lussiana, C., Perona, G., Mimosi, A., 2015 Effects of stocking density and environmental enrichment on behavior and fecal corticosteroid levels of pigs under commercial farm conditions. J. Vet. Behav. Clin. Appl. Res. 10, 569-576. http://dx.doi.org/10.1016/j.jveb.2015.05.002.

de Jong, I.C., Prelle, I.T., van de Burgwal, J.A., Lambooij, E., Korte, S.M., Blokhuis, H.J. Koolhaas, J.M., 2000. Effects of environmental enrichment on behavioral responses to novelty, learning, and memory, and the circadian rhythm in cortisol in growing pigs. Physiol. Behav. 68, 571-578. http://dx.doi.org/10.1016/S0031-9384(99) 00212-7.

de Visser, L., Baars, A.M., Lavrijsen, M., van der Weerd, C.M.M., van den Bos, R., 2011a Decision-making performance is related to levels of anxiety and differential recruitment of frontostriatal areas in male rats. Neuroscience 184, 97-106. http://dx. doi.org/10.1016/j.neuroscience.2011.02.025

de Visser, L., Homberg, J.R., Mitsogiannis, M., Zeeb, F.D., Rivalan, M., Fitoussi, A., Galhardo, V., van den Bos, R., Winstanley, C.A., Dellu-Hagedorn, F., 2011b. Rodent versions of the Iowa gambling task: opportunities and challenges fort the understanding of decision-making. Front. Neurosci. 5, 21. http://dx.doi.org/10. 3389/fnins.2011.00109.

de Vries, M., Holland, R.W., Witteman, C.L.M., 2008. In the winning mood: affect in the Iowa gambling task. Judgm. Decis. Mak. 3, 42-50.

Désiré, L., Boissy, A., Veissier, I., 2002. Emotions in farm animals: a new approach to animal welfare in applied ethology. Behav. Process. 60, 165-180.

Davenport, M.D., Tiefenbacher, S., Lutz, C.K., Novak, M.A., Meyer, J.S., 2006. Analysis of endogenous cortisol concentrations in the hair of rhesus macaques. Gen. Comp. Endocrinol. 147, 255-261. http://dx.doi.org/10.1016/j.ygcen.2006.01.005.

Dawkins, M.S., 1990. From an animal's point of view: motivation, fitness and animal welfare. Behav. Brain Sci. 13, 1-9. http://dx.doi.org/10.1017/S0140525x00077104.

Douglas, C., Bateson, M., Walsh, C., Bédué, A., Edwards, S.A., 2012. Environmental enrichment induces optimistic cognitive biases in pigs. Appl. Anim. Behav. Sci. 139, 65-73. http://dx.doi.org/10.1016/j.applanim.2012.02.018.

Duncan, I.J., Petherick, J.C., 1991. The implications of cognitive processes for animal welfare. J. Anim. Sci. 69, 5017-5022 1991.69125017x.

Ernst, K., Puppe, B., Schön, P.C., Manteuffel, G., 2005. A complex automatic feeding system for pigs aimed to induce successful behavioural coping by cognitive adaptation. Appl. Anim. Behav. Sci. 91, 205-218. http://dx.doi.org/10.1016/j. applanim.2004.10.010.

Farhoody, P., 2012. A framework for solving behavior problems. Vet. Clin. North Am. Small Anim. Pract. 15, 399-411. http://dx.doi.org/10.1016/j.cvex.2012.06.002.

Field, D.T., Williams, C.M., Butler, L.T., 2011. Consumption of cocoa flavanols results in an acute improvement in visual and cognitive functions. Physiol. Behav. 103, 255-260. http://dx.doi.org/10.1016/j.physbeh.2011.02.013.

Garon, N., Moore, C., Waschbusch, D.A., 2006. Decision making in children with ADHD Only, ADHD-anxious/depressed, and control children using a child version of the Iowa Gambling Task. J. Atten. Disord. 9, 607-619. http://dx.doi.org/10.1177/ 1087054705284501.

Gieling, E.T., Antonides, S., Fink-Gremmels, J., ter Haar, K., Kuller, W.I., Meijer, E., Nordquist, R.E., Stouten, J.M., Zeinstra, E., van der Staay, F.J., 2014. Chronic allopurinol treatment during the last trimester of pregnancy in sows: effects on low and normal birth weight offspring. PLoS One 9, e86396. http://dx.doi.org/10.1371/ journal.pone.0086396.

Grimberg-Henrici, C.G., Vermaak, P., Bolhuis, J.E., Nordquist, R.E., van der Staay, F.J., 2016. Effects of environmental enrichment on cognitive performance of pigs in a spatial holeboard discrimination task. Anim. Cognit. 19, 271-283. http://dx.doi.org/ 10.1007/s10071-015-0932-7.

Hunter, S.A., Bay, M.S., Martin, M.L., Hatfield, J.S., 2002. Behavioral effects of environmental enrichment on harbor seals (phoca vitulina concolor) and gray seals 
(halichoerus grypus). Zoo Biol. 21, 375-387. http://dx.doi.org/10.1002/zoo.10042.

Jensen, P., Toates, F.M., 1993. Who needs behavioural needs? Motivational aspects of the needs of animals. Appl. Anim. Behav. Sci. 37, 161-181. http://dx.doi.org/10.1016/ 0168-1591(93)90108-2.

Jensen, M.B., Studnitz, M., Halekoh, U., Pedersen, L.J., Jørgensen, E., 2008. Pigs' preferences for rooting materials measured in a three-choice maze-test. Appl. Anim. Behav. Sci. 112, 270-283. http://dx.doi.org/10.1016/j.applanim.2007.07.012.

Kempermann, G., Kuhn, H.G., Gage, F.H., 1997. More hippocampal neurons in adult mice living in an enriched environment. Nature 386, 493-495.

Kobayakawa, M., Koyama, S., Mimura, M., Kawamura, M., 2008. Decision making in Parkinson's disease: analysis of behavioral and physiological patterns in the Iowa Gambling Task. Mov. Disord. 23, 547-552. http://dx.doi.org/10.1002/mds.21865.

Korte, S.M., Olivier, B., Koolhaas, J.M., 2007. A new animal welfare concept based on allostasis. Physiol. Behav. 92, 422-428. http://dx.doi.org/10.1016/j.physbeh.2006. 10.018.

Krain, A.L., Wilson, A.M., Arbuckle, R., Castellanos, F.X., Milham, M.P., 2006. Distinct neural mechanisms of risk and ambiguity: a meta-analysis of decision- making. Neuroimage 32. http://dx.doi.org/10.1016/j.neuroimage.2006.02.047.

Laughlin, K., Mendl, M., 2004. Costs of acquiring and forgetting information affect spatial memory and its susceptibility to interference. Anim. Behav. 68, 97-103. http://dx. doi.org/10.1016/j.anbehav.2003.10.019.

Lee, D.Y., Kim, E., Choi, M.H., 2015. Technical and clinical aspects of cortisol as a biochemical marker of chronic stress. BMP Rep. 48, 209-216. http://dx.doi.org/10. 5483/BMBRep.2015.48.4.275.

Linnet, J., Møller, A., Peterson, E., Gjedde, A., Doudet, D., 2010. Dopamine release in ventral striatum during Iowa Gambling Task performance is associated with increased excitement levels in pathological gambling. Addiction 106, 383-390. http://dx.doi.org/10.1111/j.1360-0443.2010.03126.x.

Matsuzawa, D., Shirayama, Y., Niitsu, T., Hashimoto, K., Iyo, M., 2015. Deficits in emotion based decision-making in schizophrenia; a new insight based on the Iowa Gambling Task. Prog. Neuropsychopharmacol. Biol. Psychiatry 57, 52-59. http://dx. doi.org/10.1016/j.pnpbp.2014.10.007.

Melfi, V., 2013. Is training zoo animals enriching? Appl. Anim. Behav. Sci. 147, 299-305. http://dx.doi.org/10.1016/j.applanim.2013.04.011.

Mendl, M., Paul, E.S., 2004. Consciousness, emotion and animal welfare: insights from cognitive science. Anim. Welf. 13, S17-S25.

Merlot, E., Mounier, A.M., Prunier, A., 2011. Endocrine response of gilts to various common stressors: a comparison of indicators and methods of analysis. Physiol. Behav. 102, 259-265. http://dx.doi.org/10.1016/j.physbeh.2010.11.009.

Mills Brown, S., Klaffenböck, M., Macleod Nevison, I., Lawrence, A.B., 2015. Evidence for litter differences in play behaviour in pre-weaned pigs. Appl. Anim. Behav. Sci. 172, 17-25. http://dx.doi.org/10.1016/j.applanim.2015.09.007.

Miu, A.C., Heilman, R.M., Houser, D., 2008. Anxiety impairs decision-making: psychophysiological evidence from an Iowa Gambling Task. Biol. Psychol. 77, 353-358. http://dx.doi.org/10.1016/j.biopsycho.2007.11.010.

Mora, C., Davison, M., 2009. Conditioning as a technique for studying the sensory systems involved in animal orientation, homing and navigation. J. Navig. 62, 571-585. http://dx.doi.org/10.1017/S0373463309990063.

Moreira, N., Brown, J.L., Moraes, W., Swanson, W.F., Monteiro-Filho, E.L.A., 2007. Effect of housing and environmental enrichment on adrenocortical activity, behavior and reproductive cyclicity in the female tigrina (leopardus tigrinus) and margay (leopardus wiedii). Zoo Biol. 26, 441-460. http://dx.doi.org/10.1002/zoo.20139.

Murphy, E., Kraak, L., van den Broek, J., Nordquist, R., van der Staay, F.J., 2015. Decision-making under risk and ambiguity in low-birth-weight pigs. Anim. Cognit. 18, 561-572. http://dx.doi.org/10.1007/s10071-014-0825-1.

Must, A., Szabó, Z., Bódi, N., Szász, A., Janka, Z., Kéri, S., 2006. Sensitivity to reward and punishment and the prefrontal cortex in major depression. J. Affect. Disord. 90, 209-215. http://dx.doi.org/10.1016/j.jad.2005.12.005.

Must, A., Horvath, S., Nemeth, V.L., Janka, Z., 2013. The Iowa Gambling Task in depression-what have we learned about sub-optimal decision-making strategies? Front. Psychol. 4 (6). http://dx.doi.org/10.3389/fpsyg.2013.00732.

Oesterwind, S., Nürnberg, G., Puppe, B., Langbein, J., 2016. Impact of structural and cognitive enrichment on the learning performance, behavior and physiology of dwarf goats (Capra aegagrus hircus). Appl. Anim. Behav. Sci. 177, 34-41. http://dx.doi. org/10.1016/j.applanim.2016.01.006.

Ohl, F., van der Staay, F.J., 2012. Animal welfare: at the interface between science and society. Vet. J. 192, 13-19. http://dx.doi.org/10.1016/j.tvjl.2011.05.019.

Oitzl, M.S., de Kloet, E.R., 1992. Selective corticosteroid antagonists modulate specific aspects of spatial orientation learning. Behav. Neurosci. 106, 62-71.

Orsini, C.A., Moorman, D.E., Young, J.W., Setlow, B., Floresco, S.B., 2015. Neural mechanisms regulating different forms of risk-related decision-making: insights from animal models. Neurosci. Biobehav. Rev. 58, 147-167. http://dx.doi.org/10.1016/j. neubiorev 2015.04.009.

Paylor, R., Morrison, S.K., Rudy, J.W., Waltrip, L.T., Wehner, J.M., 1992. Brief exposure to an enriched environment improves performance on the Morris water task and increases hippocampal cytosolic protein kinase $\mathrm{C}$ activity in young rats. Behav. Brain Res. 52, 49-59. http://dx.doi.org/10.1016/S0166-4328(05)80324-9.

Pigs decree - Dutch Government, 2015. Besluit houders van dieren. § 4. Houden van varkens voor productie [WWW Document]. URL http://wetten.overheid.nl/ BWBR0035217/volledig/geldigheidsdatum_27-08-2015\#Hoofdstuk2 (Accessed 8 April 2015).

Rampon, C., Tang, Y.-P., Goodhouse, J., Shimizu, E., Kyin, M., Tsien, J.Z., 2000. Enrichment induces structural changes and recovery from nonspatial memory deficits in CA1 NMDAR1-knockout mice. Nat. Neurosci. 3, 238-244. http://dx.doi.org/10. $1038 / 72945$
Rivalan, M., Ahmed, S.H., Dellu-Hagedorn, F., 2009. Risk-prone individuals prefer the wrong options on a rat version of the Iowa Gambling Task. Biol. Psychiatry 66, 743-749. http://dx.doi.org/10.1016/j.biopsych.2009.04.008.

Rushen, J., 1996. Using aversion learning techniques to assess the mental state, suffering, and welfare of farm animals. J. Anim. Sci. 74, 1990-1995 1996.7481990x.

Sørensen, D.B., 2010. Never wrestle with a pig. Lab. Anim. 44, 159-161. http://dx.doi. org/10.1258/la.2010.009100.

Scholman, L., 2012. The Effects of Prolonged Prenatal Treatment with Oxidative Stress Reducer Allopurinol in Low Birth Weight Piglets on Measures of Chronic Stress and Learning Performance (MSc Thesis Biology). University Utrecht, Faculty of Veterinary Medicine, Emotion \& Cognition group, Utrecht, The Netherlands.

Short, S.J., Stalder, T., Marceau, K., Entringer, S., Moog, N.K., Shirtcliff, E.A., Wadhwa, P.D., Buss, C., 2016. Correspondence between hair cortisol concentrations and 30dayintegrated daily salivary and weekly urinary cortisol measures. Psychoneuroendocrinology 71, 12-18. http://dx.doi.org/10.1016/j.psyneuen.2016. 05.007 .

Sneddon, I.A., Beattie, V.E., Dunne, L., Neil, W., 2000. The effect of environmental enrichment on learning in pigs. Anim. Welf. 9, 373-383.

Sokolov, A.N., Pavlova, M.A., Klosterhalfen, S., Paul Enck, P., 2013. Chocolate and the brain: neurobiological impact of cocoa flavanols on cognition and behavior. Neurosci. Biobehav. Rev. 37, 2445-2453. http://dx.doi.org/10.1016/j.neubiorev.2013.06.013.

Starcke, K., Brand, M., 2012. Decision making under stress: a selective review. Neurosci. Biobehav. Rev. 36, 1228-1248. http://dx. doi.org/10.1016/j.neubiorev. 2012.02.003.

Studnitz, M., Bak Jensen, M., Pedersen, L.J., 2007. Why do pigs root and in what will they root? A review on the exploratory behaviour of pigs in relation to environmental enrichment. Appl. Anim. Behav. Sci. 107, 183-197. http://dx.doi.org/10.1016/j. applanim.2006.11.013.

Suhr, J.A., Tsanadis, J., 2007. Affect and personality correlates of the Iowa Gambling Task. Personal. Individ. Differ. 43, 27-36. http://dx.doi.org/10.1016/j.paid.2006.11. 004.

Tchanturia, K., Liao, P.-C., Uher, R., Lawrence, N., Treasure, J., Campbell, I.C., 2007. An investigation of decision making in anorexia nervosa using the Iowa Gambling Task and skin conductance measurements. J. Int. Neuropsychol. Soc. 13, 635-641. http:// dx.doi.org/10.1017/S1355617707070798.

Turner, S.P., Allcroft, D.J., Edwards, S.A., 2003. Housing pigs in large social groups: a review of implications for performance and other economic traits. Livest. Prod. Sci. 82, 39-51. http://dx.doi.org/10.1016/S0301-6226(03)00008-3.

van Hoek, C.S., King, C.E., 1997. Causation and influence of environmental enrichment on feather picking of the crimson-bellied conure (pyrrhura perlata perlata). Zoo Biol. 16, 161-172. http://dx.doi.org/10.1002/(SICI)1098-2361(1997)16:2<161:AIDZOO6 > 3.0.CO; $2-8$.

van Praag, H., Christie, B.R., Sejnowski, T.J., Gage, F.H., 1999. Running enhances neurogenesis, learning, and long-term potentiation in mice. Proc. Natl. Acad. Sci. U. S. A. 96, 13427-13431. http://dx.doi.org/10.1073/pnas.96.23.13427.

van den Bos, R., van der Harst, J., Jonkman, S., Schilders, M., Spruijt, B., 2006. Rats assess costs and benefits according to an internal standard. Behav. Brain Res. 171, 350-354. http://dx.doi.org/10.1016/j.bbr.2006.03.035.

van den Bos, R., Koot, S., de Visser, L., 2014. A rodent version of the Iowa Gambling Task: 7 years of progress. Front. Psychol. 5, 6. http://dx.doi.org/10.3389/fpsyg.2014. 00203.

van der Staay, F.J., Rutten, K., Erb, C., Blokland, A., 2011. Effects of the cognition impairer MK-801 on learning and memory in mice and rats. Behav. Brain Res. 220, 215-229. http://dx.doi.org/10.1016/j.bbr.2011.01.052.

van der Staay, F.J., Schoonderwoerd, A.J., Stadhouders, B., Nordquist, R.E., 2016. Overnight social isolation in pigs decreases salivary cortisol but does not impair spatial learning and memory or performance in a decision-making task. Front. Vet. Sci. - Anim. Behav. Welf. 2, 13. http://dx.doi.org/10.3389/fvets.2015.00081.

Verdejo-Garcia, A., Benbrook, A., Funderburk, F., David, P., Cadet, J.-L., Bolla, K.I., 2007. The differential relationship between cocaine use and marijuana use on decisionmaking performance over repeat testing with the Iowa Gambling Task. Drug Alcohol Depend. 90, 2-11. http://dx.doi.org/10.1016/j.drugalcdep.2007.02.004.

Yamada, T., Yamada, Y., Okano, Y., Terashima, T., Yokogoshi, H., 2009. Anxiolytic effects of short- and long-term administration of cacao mass on rat elevated T-maze test. J. Nutr. Biochem. 20, 948-955. http://dx.doi.org/10.1016/j.jnutbio.2008.08.007.

Young, J.W., van Enkhuizen, J., Winstanley, C.A., Geyer, M.A., 2011. Increased risktaking behavior in dopamine transporter knockdown mice: further support for a mouse model of mania. J. Psychopharmacol. (Oxf.) 25, 934-943. http://dx.doi.org/ $10.1177 / 0269881111400646$

Zebunke, M., Puppe, B., Langbein, J., 2013. Effects of cognitive enrichment on behavioural and physiological reactions of pigs. Physiol. Behav. 118, 70-79. http:// dx.doi.org/10.1016/j.physbeh.2013.05.005.

Zeeb, F.D., Wong, A.C., Winstanley, C.A., 2013. Differential effects of environmental enrichment, social-housing, and isolation-rearing on a rat gambling task: dissociations between impulsive action and risky decision-making. Psychopharmacology (Berl.) 225, 381-395. http://dx.doi.org/10.1007/s00213-0122822-x.

Zeinstra, E.C., Oeben, L., van der Staay, F.J., Nordquist, R.E., 2015. Methoden voor de bepaling van corticosteron in veren en cortisol in haren als een mogelijke langetermijn indicator voor dierenwelzijn (Methods for determining corticosteron in feathers and cortisol in hair as putative long-term indicator of animal welfare). Biotechniek 54, 17-22.

Zupan, M., Rehn, T., de Oliveira, D., Keeling, L.J., 2016. Promoting positive states: the effect of early human handling on play and exploratory behaviour in pigs. Animal 10, 135-141. http://dx.doi.org/10.1017/S1751731115001743. 